\title{
Occurrences and geochemical properties of clay-enriched layers in the Yellow River Delta: Implications for carbon sequestration
}

\author{
YuAN Li ${ }^{1}$, Yongming Luo ${ }^{1,2^{*}}$ \\ ${ }^{1}$ Key Laboratory of Coastal Environmental Processes and \\ Ecological Remediation, Yantai Institute of Coastal Zone \\ Research, Chinese Academy of Sciences, Yantai 264003, \\ China; yli@yic.ac.cn \\ ${ }^{2}$ Institute of Soil Science, Chinese Academy of Sciences, \\ Nanjing 210008,China; ymluo@issas.ac.cn \\ * Corresponding author
}

Clay-enriched layers occurring in deltas are important as they reveal erosion, transportation and deposition of source materials from the basin to the coast. In the Yellow River Delta a red clay layer (RCL) with a thickness of $5-50 \mathrm{~cm}$ at 1 $\mathrm{m}$ depth in the soil profile occurs in the floodplain area dominated by fluvo-aquic soil derived from Yellow River sediments. The RCL typically has a median grain size of $<20$ $\mu \mathrm{m}$, redness $\left(\mathrm{a}^{*}\right)$ of $>7$, and relatively high contents of illite, calcite and iron oxides. In the Loess-Yellow River sedimentYellow River Delta soil continuum a regime of weathering, mechanical sorting and dilution by carbonates and silica have been important factors altering the elemental geochemistry. The abundance of secondary minerals and deficiencies of silica and zircon in the RCL suggest that it was separated from a mixed source and was likely derived from highly weathered sediments (such as paleosol) from the basin. Large variations in elemental ratios have been found in the RCL characterized by excess nitrogen and trace metals and phosphorus deficiency due to adsorption and weathering effects.

The contents and stocks of SOC and SIC in the subsoil were significantly enhanced in the red clay layer (RCL). The highly reactive, secondary minerals and iron oxides are capable of stabilizing younger $\mathrm{OC}$ in transportation, deposition and post-pedogenic alteration. ${ }^{14} \mathrm{C}$ activity demonstrates that modern autochthonous $\mathrm{OC}$ derived from plant litter is the main component of OC in wetland topsoil, while millennia-old allochthonous terrestrial $\mathrm{OC}$ is the main component of OC in the YSL-RCL sequence and Yellow River sediment, and fossil OC accounts for about $4-24 \%$ of total bulk SOC. The RCL formed in the fluvial-deltaic sedimentary system with both higher carbonate content and stronger weathering intensity indicates that adsorption and precipitation of atmospheric derived carbonate on finegrained suspended particulates may be important factors in carbonate accumulation. 